\title{
Original Research Article
}

\section{Prevalence of hypertension amongst employee's state insurance beneficiaries of four districts in Haryana}

\author{
Sangeeta Narang ${ }^{1}$, Mitasha Singh ${ }^{1}$, Jyoti Yadav ${ }^{1}$, Shivam Dixit ${ }^{2}$, Narendra Singh ${ }^{1 *}$
}

\begin{abstract}
${ }^{1}$ Department of Community Medicine, ESIC Medical College, Faridabad, Haryana, India
${ }^{2}$ Department of Community Medicine, MGM Medical College, Indore, Madhya Pradesh, India
\end{abstract}

Received: 12 December 2019

Revised: 19 January 2020

Accepted: 20 January 2020

\author{
*Correspondence: \\ Dr. Narendra Singh, \\ E-mail: narendra.singhv@gmail.com
}

Copyright: ( the author(s), publisher and licensee Medip Academy. This is an open-access article distributed under the terms of the Creative Commons Attribution Non-Commercial License, which permits unrestricted non-commercial use, distribution, and reproduction in any medium, provided the original work is properly cited.

\begin{abstract}
Background: Raised blood pressure (hypertension) caused an estimated 9.4 million deaths in 2010. 22\% of adults aged 18 years and over around the world had raised blood pressure in 2014 In India prevalence of Hypertension is 22.4\% (13.5\% in Haryana, district Faridabad) according to National Family Health Survey 2015-2016. A number of studies have estimated the prevalence of hypertension in general population in our country but data regarding the prevalence of hypertension in industrial workers has not been documented in the recent past. The objectives of the study were to calculate the prevalence of hypertension and its associated risk factors in employee's state insurance (ESI) beneficiaries in four districts in Haryana.

Methods: Cross-sectional study was done on 365 ESI beneficiaries working in industries in four districts of Haryana. Predesigned structured self-administered questionnaire was used for interview. Blood pressure measurement and all the anthropometric measurements were done by the following standardized technique.

Results: The overall prevalence of hypertension was found to be $17.26 \%$. The severity of hypertension increased significantly with age $(\mathrm{p}=0.006)$. Overweight and obese participants had higher proportion of hypertensive, however, history of shift duty, drug abuse, tobacco and alcohol intake did not show a significant trend of severity of HTN.

Conclusions: From the results of the present study, it can be concluded that there are a large number of undiagnosed cases of hypertension amongst employee's state insurance corporation (ESIC) beneficiaries. It is, therefore recommended that health check-up and awareness camps should be conducted on regular basis for early detection and timely treatment of hypertension.
\end{abstract}

Keywords: Employees state insurance corporation, Body mass index, Obesity, Hypertension

\section{INTRODUCTION}

Hypertension (HTN) has been long recognized as one of the major risk factors for cardiovascular disease and premature deaths worldwide, and is one of the most common lifestyle 'silent killer' diseases. Raised blood pressure caused an estimated 9.4 million deaths in 2010. $22.5 \%$ of adults aged 18 years and over around the world had raised blood pressure (defined as systolic and/or diastolic blood pressure $>-140 / 90 \mathrm{~mm} \mathrm{Hg}$ ) in $2014 .{ }^{1}$
Usually there are no symptoms of high blood pressure and it is diagnosed after suffering a heart attack or stroke or kidney disease.

In India, it exerts substantial public health burden on cardiovascular health status and the health care system. HTN is estimated to account for $10.8 \%$ of all the deaths and $4.6 \%$ of disability-adjusted life year (DALY) in the country. It is estimated that $16 \%$ of ischaemic heart disease, $21 \%$ of peripheral vascular disease, $24 \%$ of acute myocardial infarctions and $29 \%$ of strokes are attributed 
to $\mathrm{HTN}^{2}$ According to National Family Health Survey 2015-2016, prevalence of HTN is $22.4 \%$ for both men and women in India In Haryana district Faridabad it is found to be $13.5 \% .^{3}$

A number of studies have been conducted in general population in India but data regarding the prevalence of HTN in industrial workers has not been documented in the recent past.

The objective of the study was to calculate the prevalence of HTN and its associated risk factors among employee's state insurance (ESI) beneficiaries in four districts of Haryana.

\section{METHODS}

\section{Study design, setting and sample size}

Cross-sectional study was done using health camp approach in industries in four districts of Haryana (Faridabad, Palwal, Gurgaon and Kurukshetra) during period of February 2019 to October 2019. All employee's state insurance corporation (ESIC) beneficiaries who were present and willing for the study were interviewed and examined. The minimum sample size was calculated using Epi Info v.7. Presence of HTN in district Faridabad was taken as $13.6 \%$ from NFHS-4 report at 5\% absolute error and $95 \%$ confidence interval.

\section{Inclusion criteria}

This study includes all workers in industries visited by us aged 19 to 60 years and who gave consent for study.

\section{Exclusion criteria}

Workers who did not consented were excluded.

\section{Study tool}

A-predesigned pre-tested semi structured self questionnaire was used by surveyors to obtain the needed information on socio demographic profile of interview. Blood pressure (BP) measurement was done using standard android dial BP apparatus in sitting position in right arm. ${ }^{4}$ Two readings were taken at 5 minutes interval and higher BP reading was considered for study. HTN classification was done as follows: in mild, systolic 140 to $159 \mathrm{~mm}$ of $\mathrm{Hg}$ and diastolic 90 to 99 , in moderate, systolic 160 to $179 \mathrm{~mm}$ of $\mathrm{Hg}$ and/or diastolic 100 to 109 , in severe, systolic 180 or above $\mathrm{mm}$ of $\mathrm{Hg}$ and/or diastolic 110 or more. ${ }^{2}$ All the anthropometric measurements were done by the following standardized technique. BMI was calculated by dividing the subjects mass by the square of his or her height, typically expressed in metric units $\mathrm{kg} / \mathrm{m}^{2}$. WHO classification was done as follows: BMI <18.5 (underweight), 18.5 to 24.9 (normal weight), 25 to 29.9 (overweight), >30 (obese). ${ }^{5}$ The waist circumference was measured at the midpoint between the lower margin of the last palpable ribs and the top of the iliac crest, using a stretch-resistant tape. Hip circumference was measured around the widest portion of the buttocks, with the tape parallel to the floor. For both measurements, the individual was made to stand with feet close together, arms at the side and body weight evenly distributed and measurements were taken at the end of a normal respiration. ${ }^{6}$ Abdominal obesity is defined as a waist-hip ratio above 0.90 for males and above 0.85 for females, or a body mass index (BMI) above 30.0. ${ }^{7}$ Health education on modifiable risk factors was given to the participants at the end of data collection and participants who needed medical care were referred to ESI dispensary or hospital for appropriate management.

\section{Ethical considerations}

Ethical approval was obtained from the Ethics committee of the ESIC medical college, Faridabad (134/A/11/16/ Academics/2018/130). Informed consent was taken from the beneficiaries who attended the health check-up camps. Those who were found to have HTN were referred to the ESI dispensary or ESI Hospital for management.

\section{Data and statistical analysis}

Data collected was entered in Microsoft excel software and checked for missing data. After removing the missing data the descriptive analysis of data was done using Epi info v7. Categorical variables are presented as number and percentages and continuous variables as mean. The test of significance applied for qualitative data was chi square and $\mathrm{t}$ test for quantitative data. Correlation between continuous variables like blood pressure, BMI and WHR was calculated using Pearson's correlation coefficient. Level of significance was set at $5 \%$.

\section{RESULTS}

The overall prevalence of HTN among 365 ESI beneficiaries was found to be $17.26 \%$. Mild HTN was observed among $15.07 \%$ participants (Figure 1). Majority of participants were male $(76.71 \%)$. Mean BMI, waist circumference and hip circumference was higher among males as compared to females. Mean waist hip ratio of study population was 0.88 ( 0.89 for males and 0.86 for females). Mean systolic and diastolic BP was significantly higher among males as compared to females (p: 0.021 and 0.045 respectively). The mean systolic BP of all the participants was 126.45 (127.37 in males and 123.42 in females) and mean diastolic BP was 81.06 (81.64 in males and 79.16 in females) (Table 1).

The severity of HTN increased significantly with age (p: 0.006). Females had higher proportion of moderate (3.5\%) and severe (1.2\%) HTN as compared to males $(\mathrm{p}=0.167)$. Overweight and obese participants had higher proportion of hypertensive however no significant trend was observed with severity of HTN. History of shift duty, 
drug abuse, tobacco and alcohol intake did not show a significant trend of severity of HTN (Table 2).

Table 1: Physical characteristics of male and female subjects.

\begin{tabular}{|llll|}
\hline Parameter & $\begin{array}{l}\text { Male } \\
(\mathbf{n = 2 8 0})\end{array}$ & $\begin{array}{l}\text { Female } \\
(\mathbf{n = 8 5})\end{array}$ & P value \\
\hline Age $($ in years) & $33.83 \pm 10.40$ & $39.05 \pm 8.62$ & $<0.0001$ \\
\hline Weight & $63.64 \pm 11.03$ & $55.21 \pm 11.36$ & $<0.0001$ \\
\hline Height & $167.69 \pm 6.32$ & $156.59 \pm 9.64$ & $<0.0001$ \\
\hline BMI $\left(\mathbf{k g} / \mathbf{m}^{\mathbf{2}}\right)$ & $22.60 \pm 3.54$ & $22.48 \pm 4.16$ & 0.819 \\
\hline Systolic BP & $127.37 \pm 12.35$ & $123.42 \pm 17.53$ & 0.021 \\
\hline Diastolic BP & $81.64 \pm 9.10$ & $79.16 \pm 10.10$ & 0.045 \\
\hline Waist circumference $(\mathbf{c m})$ & $78.85 \pm 11.82$ & $76.04 \pm 10.24$ & 0.034 \\
\hline Hip circumference $(\mathbf{c m})$ & $88.84 \pm 12.16$ & $88.35 \pm 10.78$ & 0.724 \\
\hline Waist hip ratio & $0.89 \pm 0.06$ & $0.86 \pm 0.06$ & $<0.0001$ \\
\hline
\end{tabular}

Table 2: Socio demographic and behavioural determinants of HTN.

\begin{tabular}{|c|c|c|c|c|c|c|}
\hline \multirow{2}{*}{$\begin{array}{l}\text { Socio- } \\
\text { demographic }\end{array}$} & \multirow{2}{*}{$\begin{array}{l}\text { Normotensive } \\
\mathbf{N}(\%)\end{array}$} & \multicolumn{4}{|c|}{ Hypertensive } & \multirow{2}{*}{$\begin{array}{l}\text { Fisher's } \\
\text { exact test } \\
\text { P value }\end{array}$} \\
\hline & & Mild (\%) & Moderate (\%) & Severe $(\%)$ & Total (\%) & \\
\hline \multicolumn{7}{|l|}{ Age (in years) } \\
\hline$<20$ & $12(100)$ & 0 & 0 & 0 & $12(100)$ & \multirow{5}{*}{0.006} \\
\hline $20-29$ & $100(92.6)$ & $8(7.4)$ & 0 & 0 & $108(100)$ & \\
\hline $30-39$ & $96(82.1)$ & $19(16.2)$ & $2(1.7)$ & 0 & $117(100)$ & \\
\hline $40-49$ & $62(75.6)$ & $16(19.5)$ & $3(3.7)$ & $1(1.2)$ & $82(100)$ & \\
\hline $50-59$ & $32(69.6)$ & $12(26.1)$ & $2(4.3)$ & 0 & $46(100)$ & \\
\hline \multicolumn{7}{|l|}{ Sex } \\
\hline Male & $232(82.9)$ & $44(15.7)$ & $4(1.4)$ & 0 & $280(100)$ & \multirow{2}{*}{0.167} \\
\hline Female & $70(82.4)$ & $11(12.9)$ & $3(3.5)$ & $1(1.2)$ & $85(100)$ & \\
\hline \multicolumn{7}{|l|}{ BMI } \\
\hline Underweight & $35(92.1)$ & $3(7.9)$ & 0 & 0 & $38(100)$ & \multirow{4}{*}{0.102} \\
\hline Normal weight & $207(84.8)$ & $32(13.1)$ & $4(1.6)$ & $1(0.4)$ & $244(100)$ & \\
\hline Overweight & $53(73.6)$ & $16(22.2)$ & $3(4.2)$ & 0 & $72(100)$ & \\
\hline Obese & $7(63.6)$ & $4(36.4)$ & 0 & 0 & $11(100)$ & \\
\hline \multicolumn{7}{|l|}{ WHR } \\
\hline Normal & $168(85.7)$ & $26(13.3)$ & $2(1)$ & 0 & $196(100)$ & \multirow[b]{2}{*}{0.192} \\
\hline Central obesity & $134(79.3)$ & $29(17.2)$ & $5(3.0)$ & $1(0.6)$ & $169(100)$ & \\
\hline \multicolumn{7}{|l|}{ Shift duty } \\
\hline Yes & $164(83.7)$ & $29(14.8)$ & $3(1.5)$ & 0 & $196(100)$ & \multirow{2}{*}{0.809} \\
\hline No & $138(81.7)$ & $26(15.4)$ & $4(2.4)$ & $1(0.6)$ & $169(100)$ & \\
\hline \multicolumn{7}{|l|}{ Tobacco intake } \\
\hline Yes & $37(72.5)$ & $14(27.5)$ & 0 & 0 & $51(100)$ & \multirow{2}{*}{0.055} \\
\hline No & $265(84.4)$ & $41(13.1)$ & $7(2.2)$ & $1(0.3)$ & $314(100)$ & \\
\hline \multicolumn{7}{|l|}{ Alcohol intake } \\
\hline Yes & $58(85.3)$ & $10(14.7)$ & 0 & 0 & $68(100)$ & \multirow{2}{*}{0.706} \\
\hline No & $244(82.2)$ & $45(15.2)$ & $7(2.4)$ & $1(0.3)$ & $297(100)$ & \\
\hline \multicolumn{7}{|l|}{ Drug abuse } \\
\hline Yes & $7(100)$ & 0 & 0 & 0 & $7(100)$ & \multirow{2}{*}{0.659} \\
\hline No & $295(82.4)$ & $55(15.4)$ & $7(2.0)$ & $1(0.3)$ & $358(100)$ & \\
\hline \multicolumn{7}{|l|}{ Past history } \\
\hline Yes & $4(100)$ & 0 & 0 & 0 & $4(100)$ & \multirow{2}{*}{1.000} \\
\hline No & $298(82.5)$ & $55(15.2)$ & $7(1.9)$ & $1(0.3)$ & $361(100)$ & \\
\hline \multicolumn{7}{|l|}{ Family history } \\
\hline Yes & $1(50.0)$ & $1(50.0)$ & 0 & 0 & $2(100)$ & \multirow{2}{*}{0.316} \\
\hline No & $301(82.9)$ & $54(14.9)$ & $7(1.9)$ & $1(0.3)$ & $363(100)$ & \\
\hline
\end{tabular}

Continued. 


\begin{tabular}{|c|c|c|c|c|c|c|}
\hline \multirow{2}{*}{$\begin{array}{l}\text { Socio- } \\
\text { demographic }\end{array}$} & \multirow{2}{*}{$\begin{array}{l}\text { Normotensive } \\
\text { N (\%) }\end{array}$} & \multicolumn{4}{|c|}{ Hypertensive } & \multirow{2}{*}{$\begin{array}{l}\text { Fisher's } \\
\text { exact test } \\
\text { P value }\end{array}$} \\
\hline & & Mild (\%) & Moderate (\%) & Severe (\%) & Total (\%) & \\
\hline \multicolumn{7}{|c|}{ Treatment history } \\
\hline Yes & $2(100)$ & 0 & 0 & 0 & $2(100)$ & \multirow{2}{*}{1.000} \\
\hline No & $300(82.6)$ & $55(15.2)$ & $7(1.9)$ & $1(0.3)$ & $363(100)$ & \\
\hline
\end{tabular}

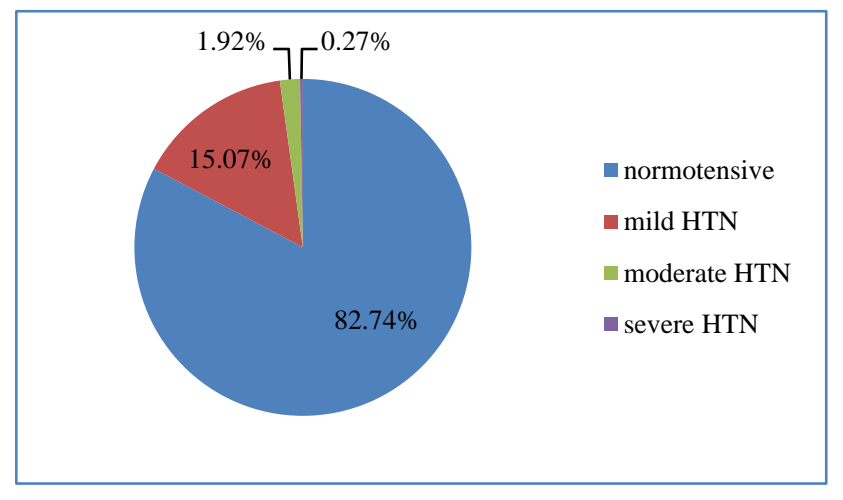

Figure 1: Distribution of study participants as per severity of hypertension.

\section{DISCUSSION}

In the present study the overall prevalence of HTN was found to be $17.26 \%$. The observed prevalence of HTN in this study is representative of population who are working and in age group below 60 yrs.

Kishore et al also reported similar findings i.e. prevalence rate of $14.1 \%$ in rural Delhi. ${ }^{8}$ However, higher prevalence rates $(29.8 \%)$ have been estimated by Anchala et al based on their review and meta-analysis of studies on HTN. ${ }^{9}$ Prakash et al also found $36.4 \%$ of the participants to be hypertensive in their study carried out in policemen posted in Rohtak. ${ }^{10}$

The rising prevalence of overweight and obesity in India has a direct correlation with the increasing prevalence of obesity-related co-morbidities; HTN, the metabolic syndrome, dyslipidemia, type 2 diabetes mellitus, and cardiovascular disease. ${ }^{11}$ Both generalized and abdominal obesity are associated with increased risk of morbidity and mortality. The main cause of obesity-related deaths is CVD, for which abdominal obesity is a predisposing factor. ${ }^{12}$ According to ICMR-INDIAB study, prevalence rate of obesity and central obesity varies from 11.8 to $31.3 \%$ and 16.9 to $36.3 \% .^{3}$ In this study findings are almost similar. The prevalence of obesity was found to be $22.74 \%$ and abdominal obesity was found in $34.29 \%$ males and $16.47 \%$ females. However, Krishna et al have reported higher prevalence of generalized, abdominal and combined obesity $(56 \%, 71.2 \%$ and $51.3 \%$ respectively) a community based cross-sectional study conducted among 309 people in the rural field practice area of their medical college from January to March, 2017. ${ }^{11}$
Amongst the study participants in the current study, the severity of HTN increased significantly with age $(\mathrm{p}=0.006)$. History of shift duty, drug abuse, tobacco and alcohol intake did not show a significant trend of severity of HTN. Overweight and obese participants had higher proportion of hypertensive. Shikha et al reported that gender, age, marital status, occupation, education status, tobacco use and physical activity was significantly associated with the hypertensive states. ${ }^{13}$ They found a positive correlation between increasing BMI and increasing rate of HTN.

\section{Limitations}

Since it is a cross sectional study, causal association cannot be established between HTN and different study variables. This study was conducted on working population i.e. ESI beneficiaries in industries itself. Their families and dependents in houses were not included in the study.

\section{CONCLUSION}

From the results of the present study, it can be concluded that there are a large number of undiagnosed cases of HTN amongst ESIC beneficiaries. These workers constitute an important workforce of our country. Therefore, recommended that health check-up and awareness camps should be conducted on regular basis for early detection and timely treatment of HTN. Timely intervention in the form of drug therapy and regular monitoring of blood pressure will decrease the morbidity in these beneficiaries. It will also lead to increased productivity of these workers. Each camp was followed by health education session on HTN.

\section{ACKNOWLEDGEMENTS}

The authors are grateful to the Dean, ESIC Medical College, Faridabad who gave permission to carry out this study. The authors thank all ESIC beneficiaries who have participated in this study.

\section{Funding: No funding sources}

Conflict of interest: None declared

Ethical approval: The study was approved by the Institutional Ethics Committee

\section{REFERENCES}

1. Global NCD Target- reduce high blood pressure. World Health Organization. 2016. 
2. National Family Health Survey. 2015-2016.

3. Hypertension: The Silent Killer. Department of Health Research - Ministry of Health \& Family Welfare Government of India. Indian Council Med Res. Available at: https://www.icmr.nic.in/sites/ default/files/press_realease_files/Hypertension.pdf. Accessed on 3 June 2019.

4. Gupta R, Venkata S. Hypertension epidemiology in India emerging aspects. Current Opinion Cardiol. 2019;34(4):331-1.

5. Wikipedia. Available at: https://en.wikipedia.org. wiki.classification-of-obesity. Accessed on 3 June 2019.

6. STEPWISE approach to surveillance (STEPS), World health organisation, Accessed on 21 March 2012.

7. Waist WHR-WHO Whqlibdoc.whoint/978924. Available at: https://www.who.int/obesity/WH. Accessed on 3 June 2019.

8. Kishore J, Gupta N, Kohli C, Kumar N. Prevalence of hypertension and determination of its Risk Factors in Rural Delhi. Int $\mathbf{J}$ Hypertension. 2016;2016:7962595.

9. Anchala R, Kannuri NK, Pant H, Khan H, Oscar H, Angelantonio E, et al. Hypertension in India: a systematic review and meta-analysis of prevalence, awareness, and control of hypertension. J Hypertens. 2014;32(6):1170-7.

10. Parkash J, Kalhan M,Singhania K, Punia A, Kumar B, Kaushal P. Prevalence of Hypertension and its Determinants among Policemen in a City of Haryana, India. Int $\mathbf{J}$ Appl Basic Med Res. 2019;9(3):143-7.

11. Undavalli VK, Chowdary S,Ponnaganti S, NarniH. Prevalence of generalized and abdominal obesity: India's big problem.International Journal of Community Medicine and Public Health Undavalli VK et al. Int J Community Med Public Health. 2018;5(4):1311-6.

12. Waist Circumference and Waist-Hip Ratio, Report of a WHO Expert Consultation (PDF). World Health Organization. 2008.

13. Singh S, Shankar R, Singh GP. Prevalence and associated Risk Factor of Hypertension:Cross Sectional Study in Urban Varansi. Int J Hypertension. 2017;2017:5491838.

Cite this article as: Narang $\mathrm{S}$, Singh $\mathrm{M}$, Yadav J, Dixit S, Singh N. Prevalence of hypertension amongst employee's state insurance beneficiaries of four districts in Haryana. Int J Community Med Public Health 2020;7:604-8. 